\title{
Traumatic Ventral Hypogastric Hernia: A Case Report and Review of Literature in Pediatrics
}

\section{Muhammad Elsayed Abdelhafez Mahmoud ${ }^{1,2 *}$}

${ }^{1}$ Pediatric Surgery Department, Al-Houssain University Hospital, Al-Azhar University, Cairo, Egypt

${ }^{2}$ Pediatric Surgery Department, Prince Mohammed bin Abdulaziz Hospital (PMAH), Riyadh, KSA

*Corresponding Author: Muhammad Elsayed Abdelhafez Mahmoud, Pediatric Surgery Department, Al-Houssain University Hospital, Al-Azhar University, Cairo, Egypt.
Received: March 16, 2020

Published: March 31, 2020

(C) All rights are reserved by Muhammad

Elsayed Abdelhafez Mahmoud.

\begin{abstract}
Background: Pediatric traumas are routinely categorized into blunt and penetrating types. Bicycle handlebar exerts a biphasic or dual effect (it is primarily a blunt mechanism but due to its focused effect, it disrupts the muscles without cutting the skin). In 1964, Roberts reported a 9-year-old boy with acquired abdominal wall hernia after a fall upon a bicycle handlebar to be the second case of traumatic abdominal wall hernia after Landry report in 1956. Since then, more than 66 pediatric cases have been reported. In dealing with cases having this type of injury, radiologic studies are warranted to reveal the injured parieties and organs, address these injuries, and achieve optimum case stabilization. Here in this article, we present our experience in management of pediatric traumatic abdominal wall hernia case and literature review.

Case Presentation: An 11-years-old boy presented to the ER of Al-Houssain university hospital with traumatic ventral hypogastric hernia caused by bicycle handlebar impact to his lower abdomen. The case was initially assessed, stabilized, managed operatively and followed until improved and became ready for discharge.

Conclusion: Traumatic abdominal wall hernias occurs in response to concentrated impact by handlebar to the abdomen leading to muscle yielding but the resilient elastic nature of the skin keeps it intact. These injuries should be suspected in the setting of suggestive trauma mechanism followed by abdominal swelling and should be dealt with timely and seriously on an individual basis to restore the disrupted anatomy.

Keywords: Traumatic Hernia; Bicycle Handlebar Injury; Ventral Hernia; Blunt Abdominal Trauma; Exploratory Laparotomy; Conservative Management
\end{abstract}

\section{Abbreviations}

ATLS: Advanced Trauma Life Support; bpm: Beat Per Minute; CT: Computed Tomography; ER: Emergency Room; Hb: Hemoglobin; Hct: Hematocrit; MVC: Motor Vehicle Collision; NGT: Nasogastric Tube; OPD: Outpatient Department; PALS: Pediatric Advanced Life Support; PICU: Pediatric Intensive Care Unit; Plt: Platelets; RBCs: Red Blood Cells; RBS: Random Blood Sugar; S: Serum; SC: Subcutaneous Tissue; US: Ultrasonography; WBCs: White Blood Cells

\section{Introduction}

Acute abdominal wall hernias caused by traumatic forces as seat belt, motor cycle, or bicycle handlebar are very rare entity [1]. Bicycle handlebar acts as biphasic (blunt and penetrating) mechanism of trauma strong enough to disrupt the abdominal wall musculature but weak enough to affect the skin thus resulting in traumatic abdominal wall hernia [2-4]. They were first described by Landry., et al. in 1956 [2]. Large portion of traumatic abdominal wall hernia cases is reported in children. Surgery is indicated for traumatic abdominal wall hernias to repair the fasciomuscular defect and possibly injured organs after case stabilization either in the emergency department or pediatric intensive care unit (PICU) for unstable cases at presentation. Prompt surgical repair is indicated to prevent incarceration or strangulation of the herniated viscera [5,6]. Here in this article, we present our experience in management of pediatric handlebar trauma victim as regard clinical scenario, diagnostic studies, operative details and follow up and also review the literature.

This article emphasizes the importance of meticulous caution during dealing with this type of abdominal injury to address the 
injured organs without missing injuries or causing additional iatrogenic injuries, and to securely close the fasciomuscular defect.

\section{Case Report}

We present a case of 11-years-old male child referred from general hospital to ER of Al-Houssain university hospital complaining of absolute constipation and vomiting since 2 days. On quick examination and anamnesis, he was found to have hypogastric swelling and ecchymosis (Figure 1) caused by bicycle handlebar impact to his lower abdomen 2 days ago upon falling on the ground after crashing with immobile truck. Primary survey revealed that he was conscious but confused, had a toxic look, pulse 120 beat per minute (bpm), temperature: $38.5^{\circ} \mathrm{C}$, intact patent airway, equal bilateral air entry, mildly hypotensive $(110 / 54 \mathrm{mmHg}$, normal age-adjusted diastolic blood pressure is 61). Secondary survey revealed that he had sutured 2 cut wounds in the forehead. Chest and Heart: No abnormality detected at time of examination. As regard the abdomen: generalized rigidity, tender contused hypogastric swelling (midway between umbilicus and symphysis pubis) with impulse on cough with gurgling sensation and bruises. He was admitted, resuscitated, and stabilized as per pediatric advanced life support (PALS) and advanced trauma life support (ATLS) protocol guidelines.

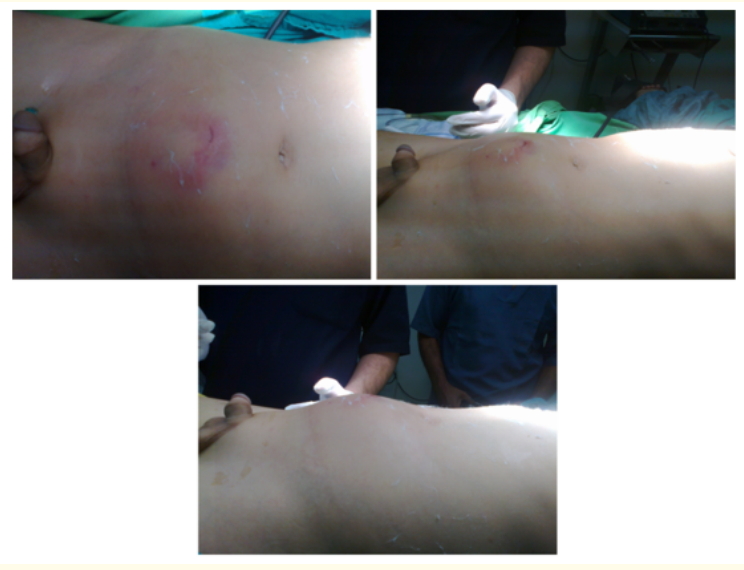

Figure 1: The patient photo showing hypogastric (suprapubic) ecchymotic bulge.

Two wide bore cannulas were inserted for resuscitation. Also, nasogastric tube (NGT) and urinary catheter were inserted. The case was investigated by laboratory tests and radiologic imaging studies.

\section{Laboratory investigations}

WBCs: $12 \times 10^{3} / \mathrm{mm}^{3}, \mathrm{Hb}: 11 \mathrm{~g} / \mathrm{dl}$, Hct: 34.6 , Plt: $279 \times 10^{3} / \mathrm{mm}^{3}$, S. creatinine: $0.8 \mathrm{mg} / \mathrm{dl}$, RBS: $98 \mathrm{mg} / \mathrm{dl}, \mathrm{pH}: 7.41$, S. sodium: 141 $\mathrm{mEq} / \mathrm{L}, \mathrm{S}$. potassium: $4.1 \mathrm{mEq} / \mathrm{L}, \mathrm{HCO}_{3}: 19.5 \mathrm{mEq} / \mathrm{L}$.
Ultrasonography (US) abdomen and pelvis

Infra-umbilical swelling (hematoma versus hernia), mild perisplenic collection.

Computed tomography (CT) abdomen and pelvis (Figure 2)

Infra-umbilical herniated bowel loops with moderate pelvic collection.

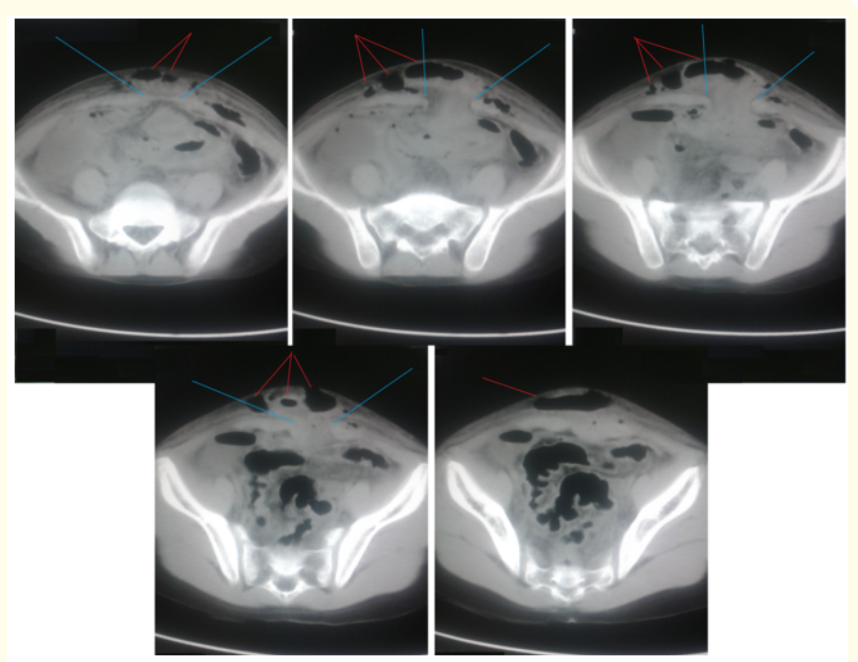

Figure 2: CT trauma scan axial sections showing herniated bowel loops (pointed to by red lines) to be intermuscular subcutaneous in the hypogastric (suprapubic) region, hematoma, and intraperitoneal fluid collection. Blue lines point to edge of the musculofascial defect

Operative details

Anaesthesia: General endotracheal with muscle relaxant.

Position: Supine.

Incision: Curvilinear Pfannenstiel incision.

Operative findings: After skin and SC tissue incision, pus was found, rectus muscle defect and an intact small bowel loop was found beneath the lower flap. With great care, muscle cut was completed till the peritoneum. Pus and stool were found filling the abdomen. Extensive adhesions and pyogenic membrane covering a large segment of small bowel were found. A big perforation (involves more than half circumference) of an ileal loop with dirty pyogenic edges approximately $150 \mathrm{~cm}$ from ileocecal junction. A subhepatic fixed cecum was also found. Palpation of the spleen revealed intact spleen with no injury.

\section{Operative procedure}

Repeated irrigation suction of the peritoneal cavity was done. Last time at the end of operation mixed with metronidazole (flagyl $^{\circledR}$ ). Adhesiolysis and appendectomy were done. Resection-anastomosis of the perforated ileal segment was done. A pelvic drain was inserted. Secure hemostasis was assured. Closure of the ab- 
dominal wound in layers anatomically was done. Smooth recovery from anaesthesia and transfer to the ward.

\section{Results and post-operative follow-up}

The patient had smooth uneventful post-operative course and dramatic improvement of the general condition occurred. Vital signs all improved. Abdomen: soft and lax with clean wound. Wound seroma developed in the $4^{\text {th }}$ post-operative day and managed conservatively. Skin and SC tissue healed nicely. Drain: revealed 50 cc serosanguinous within 36 hours then negligible amount afterwards so it was removed 2 days postoperatively. The patient passed flatus in the $2^{\text {nd }}$ post-operative day morning and stool in the same day evening many times till the $3^{\text {rd }}$ post-operative day (passed stool 3 - 4 times daily afterwards). Oral feeding was allowed on the $5^{\text {th }}$ post-operative day and well tolerated and discharged home in good stable health status. Two months later, the patient was revised at the clinic outpatient department (OPD) with good outcome (Figure 3).

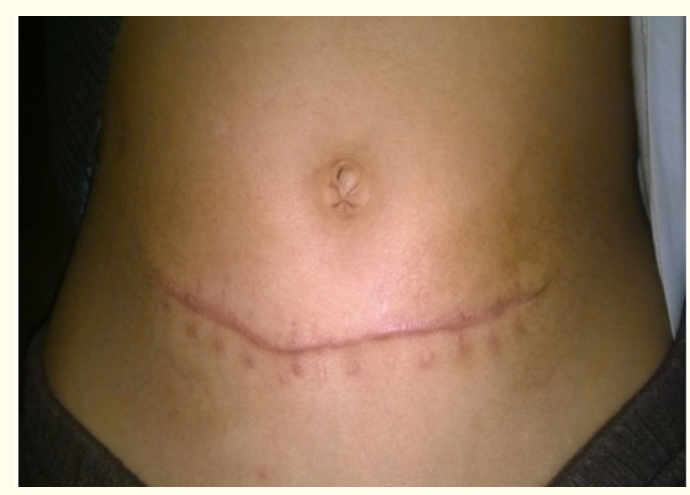

Figure 3: Appearance 2 months post operatively

\section{Discussion}

A traumatic abdominal wall hernia is defined as herniation of viscera through disrupted fascia and musculature with intact skin after focal significant trauma in absence of evidence of prior defect at the affected area $[7,8]$. It is generally caused by concise point of energy transfer such as handlebar or any other tough objects, blunt enough to penetrate the skin, but powerful enough to cause localized effect on the muscles and possibly internal viscera. In addition to the localized force, sudden increase in intra-abdominal pressure causes disruption of peritoneum, abdominal wall fascia, and muscles [4,9]. But due to its elastic resistant nature, the skin remains intact resulting in traumatic abdominal wall hernia $[4,10]$.

Wood., et al. classified traumatic abdominal hernias into 3 categories according to the size and offending etiology: Type I, small defect caused by localized blunt trauma such as bicycle handlebars; Type II, larger defects developed by high-energy transfer events such as by motor vehicle collision (MVC) or falling from height, and, rarely, Type III, intra-abdominal bowel herniation attributed to deceleration injuries [11-15].

Handlebar hernias belong to type I injuries and are rarely associated with intra-abdominal injuries [2,14]. In adults, blunt traumatic abdominal wall hernias are mainly assigned to seat belt injury in motor vehicle collisions and almost always accompanied by significant injuries. In pediatrics, bicycle handlebar abdominal injuries have high rate of associated morbidity with the typical picture of post-traumatic bruised lump under the skin. Associated injuries are uncommon because the impact is concise to single point [16].

A MEDLINE search via PubMed and Cochrane Library using keywords "handlebar hernia" and "traumatic abdominal wall hernias" revealed about 79 case reports on handlebar hernias in both pediatrics and adults (Table 1) [17].

Of these cases, 67 (84.6\%) occurred in children aged 3 to 14 years old $[4,7,13,18]$. In adults, the hernias were noticed to happen at anatomical weak points as in inguinal region or the lower abdomen lateral to rectus muscle $[14,19]$.

The site of herniation in pediatrics was more diverse, occurring mostly in the lower abdomen, with eight reports in the upper abdomen [20] and two over the rectus abdominis muscle [21]. This emphasizes the thin and weaker abdominal wall in children as a cause of the higher rate of such injury among this patients' population.

From the above table, we can conclude that 58 cases were male (86.4\%) (with age ranging from 3 to 14 years) and 9 were female (with age ranging from 4 to 12 years).

As regard the offending tool, bicycle was the cause in 63 cases, motorbike in 2 cases, motor vehicle collision in 1 case, and scooter in 1 case.

As regard the site, right lower quadrant was affected in 32 cases, left lower quadrant in 16 cases, left upper quadrant in 5 cases, right upper quadrant in 3 cases, umbilical in 4 cases, left lumbar 1 of them above iliac crest) in 3 cases, trans-rectus in 2 cases, suprapubic in 1 case, and right iliac fossa in 1 case.

As regard the management, 50 cases underwent operative repair of the defect, 1 case underwent operative repair with concomitant bowel resection-anastomosis, 7 cases underwent operative repair with concomitant closure of bowel perforation, 1 case underwent operative repair with concomitant colonic resectionanastomosis and repair of small bowel injuries, 1 case underwent operative repair with concomitant repair of ruptured bladder, 1 


\begin{tabular}{|c|c|c|c|c|c|}
\hline Case No & Author/Year & Age/Sex & Mode of Injury & Site of Trauma & Management \\
\hline 1 & Landry (1956) & $14 / \mathrm{M}$ & Motorbike & LLQ & Laparotomy \\
\hline 2 & Roberts (1964) & 9/M & Bicycle & LLQ & Layered closure \\
\hline 3 & Maunola (1965) & $9 / F$ & Bicycle & LLQ & Laparotomy \\
\hline 4 & Pendl (1970) & $8 / F$ & Bicycle & RLQ & Layered closure \\
\hline 5 & Herbert (1973) & $7 / \mathrm{M}$ & Bicycle & LLQ & Layered closure \\
\hline 6 & Hollwarth (1977) & $4 / F$ & Scooter & RLQ & Layered closure \\
\hline 7 & Hollwarth (1977) & $6 / \mathrm{M}$ & Bicycle & RLQ & Closure \\
\hline 8 & Hollwarth (1977) & $7 / \mathrm{M}$ & Bicycle & LUQ & Closure \\
\hline 9 & Hollwarth (1977) & $13 / \mathrm{M}$ & Bicycle & Suprapubic & Closure \\
\hline 10 & Dreyfuss., et al. (1986) & $11 / \mathrm{M}$ & Bicycle & Rectus abdominis & Debridement with closure \\
\hline 11 & Peters., et al. (1988) & $9 / \mathrm{M}$ & Bicycle & Umbilical & $\begin{array}{c}\text { Laparotomy with closure of jejunal perfora- } \\
\text { tion with layered closure }\end{array}$ \\
\hline 12 & Schneegans (1988) & $8 / \mathrm{M}$ & Bicycle & RLQ & Layered closure \\
\hline 13 & Mitchiner (1990) & $7 / \mathrm{M}$ & Bicycle & LUQ & Layered closure \\
\hline 14 & Damschen., et al. (1994) & $5 / \mathrm{M}$ & Bicycle & RLQ & Layered closure \\
\hline 15 & Kubalak (1994) & $6 / \mathrm{M}$ & Bicycle & RLQ & Closure \\
\hline 16 & Kubalak (1994) & $9 / \mathrm{F}$ & Bicycle & RLQ & Closure \\
\hline 17 & Luchtman., et al. (1997) & $7 / \mathrm{M}$ & Bicycle & RLQ & Closure \\
\hline 18 & Perez., et al. (1998) & $11 / \mathrm{M}$ & Bicycle & LLQ & Laparotomy with layered closure \\
\hline 19 & Kubota., et al. (1999) & 9/M & Bicycle & RLQ & Layered closure \\
\hline 20 & Fraser., et al. (2002) & $11 / \mathrm{M}$ & Bicycle & RLQ & Layered closure \\
\hline 21 & Mancel and Aslam (2003) & $7 / \mathrm{M}$ & Bicycle & LLQ & Layered closure \\
\hline 22 & Goliath., et al. (2004) & $11 / \mathrm{M}$ & Bicycle & RLQ & Layered closure \\
\hline 23 & Prada Arias., et al. (2004) & $10 / \mathrm{M}$ & Bicycle & RLQ & Layered closure \\
\hline 24 & Prada Arias., et al. (2004) & $6 / F$ & Bicycle & RLQ & Layered closure \\
\hline 25 & Chen., et al. (2005) & 9/M & Bicycle & RLQ & Layered closure \\
\hline 26 & Iinuma., et al. (2005) & $8 / \mathrm{M}$ & Bicycle & RLQ & Appendectomy with closure \\
\hline 27 & Matsuo., et al. (2007) & 9/M & Bicycle & LLQ & Conservative \\
\hline 28 & Mezhir., et al. (2007) & $7 / \mathrm{M}$ & Bicycle & LUQ & Laparotomy with layered closure \\
\hline 29 & Haimovici., et al. (2007) & $15 / \mathrm{M}$ & Bicycle & Umbilical & Laparotomy with layered closure \\
\hline 30 & Litton., et al. (2008) & $13 / \mathrm{M}$ & Bicycle & RLQ & Conservative \\
\hline 31 & Narci., et al. (2008) & $12 / \mathrm{M}$ & Bicycle & RLQ & Layered closure \\
\hline 32 & Nguyen., et al. (2009) & $6 / \mathrm{M}$ & Bicycle & LLQ & Layered closure \\
\hline 33 & Tonsi., et al. (2010) & $14 / \mathrm{M}$ & Bicycle & RIF & $\begin{array}{l}\text { Laparotomy with jejunal resection anasto- } \\
\text { mosis }\end{array}$ \\
\hline 34 & Yegane., et al. (2010) & $4 / \mathrm{M}$ & Bicycle & RUQ & Layered closure \\
\hline 35 & Van Bemmel., et al. (2011) & $7 / \mathrm{M}$ & Bicycle & Rectus abdominis & Layered closure \\
\hline 36 & Rowell (2011) & $14 / \mathrm{M}$ & Bicycle & RUQ & Laparoscopic repair \\
\hline 37 & Mitchell., et al. (2011) & $14 / \mathrm{M}$ & Bicycle & RLQ & Layered closure \\
\hline 38 & Yan., et al. (2011) & $8 / \mathrm{M}$ & Bicycle & RLQ & Layered closure \\
\hline 39 & Hatti., et al. (2011) & $5 / \mathrm{M}$ & Bicycle & LLQ & Layered closure \\
\hline 40 & Bosemani., et al. (2011) & $11 / \mathrm{F}$ & Bicycle & RLQ & $\begin{array}{l}\text { Closure of jejunal perforation with layered } \\
\text { closure }\end{array}$ \\
\hline 41 & Bosemani., et al. (2011) & $8 / \mathrm{F}$ & Bicycle & RUQ & Layered closure \\
\hline 42 & Decker., et al. (2012) & $13 / \mathrm{M}$ & Bicycle & RLQ & Layered closure \\
\hline 43 & Thakur (2013) & 9/M & Bicycle & RLQ & Layered closure \\
\hline 44 & Upasani (2013) & $12 / \mathrm{M}$ & Bicycle & LUQ & Conservative \\
\hline 45 & Griffin., et al. (2013) & $11 / \mathrm{M}$ & Bicycle & RLQ & Layered closure \\
\hline
\end{tabular}




\begin{tabular}{|c|c|c|c|c|c|}
\hline 46 & Klimek., et al. (2013) & $12 / \mathrm{F}$ & Bicycle & Umbilical & Layered closure \\
\hline 47 & Yaylaci (2014) & $11 / \mathrm{M}$ & Bicycle & LLQ & $\begin{array}{l}\text { Closure of jejunal perforation with layered } \\
\text { closure }\end{array}$ \\
\hline 48 & Talutis., et al. (2015) & $11 / \mathrm{M}$ & Bicycle & LLQ & Layered closure \\
\hline 49 & Talutis., et al. (2015) & $9 / \mathrm{M}$ & Bicycle & RLQ & Layered closure \\
\hline 50 & Talutis., et al. (2015) & $7 / F$ & Bicycle & RLQ & $\begin{array}{l}\text { Closure of ileal perforation with layered } \\
\text { closure }\end{array}$ \\
\hline 51 & Baderalmaarif (2015) & $3 / \mathrm{M}$ & Bicycle & LLQ & Layered closure \\
\hline 52 & $\begin{array}{l}\text { Angel Buitrago and Lugo } \\
\text { Vicente, (2015) }\end{array}$ & $14 / \mathrm{M}$ & Bicycle & Umbilical & Layered closure \\
\hline 53 & Hirose., et al. (2015) & $14 / \mathrm{M}$ & Bicycle & LLQ & Layered closure \\
\hline 54 & Hirose., et al. (2015) & $13 / \mathrm{M}$ & Bicycle & RLQ & Repair of bladder rupture layered closure \\
\hline 55 & Ahmed., et al. (2015) & $8 / \mathrm{M}$ & Bicycle & RLQ & Closure \\
\hline 56 & Deepak., et al. (2015) & $12 / \mathrm{M}$ & Bicycle & LUQ & $\begin{array}{l}\text { Closure of jejunal perforation with layered } \\
\text { closure }\end{array}$ \\
\hline 57 & Deepak., et al. (2015) & $12 / \mathrm{M}$ & Bicycle & RLQ & Layered closure \\
\hline 58 & Pederiva., et al. (2016) & $9 / \mathrm{M}$ & Bicycle & LLQ & $\begin{array}{l}\text { Laparotomy with closure of ileal } \\
\text { perforation with layered closure }\end{array}$ \\
\hline 59 & Volpe., et al. (2017) & $12 / \mathrm{M}$ & Bicycle & RLQ & Conservative \\
\hline 60 & Volpe., et al. (2017) & $8 / \mathrm{M}$ & Bicycle & RLQ & Conservative \\
\hline 61 & Tianyi., et al. (2017) & 8/M & Motorbike & Left lumbar & Layered closure \\
\hline 62 & Ramos-Irizarry., et al. (2017) & $11 / \mathrm{M}$ & Bicycle & RLQ & Layered closure \\
\hline 63 & Rinaldi., et al. (2017) & $12 / \mathrm{M}$ & Bicycle & LLQ & Layered closure \\
\hline 64 & Rinaldi., et al. (2017) & $13 / \mathrm{M}$ & Bicycle & RLQ & Layered closure \\
\hline 65 & $\begin{array}{l}\text { Maria Aggelidou et al, } \\
\text { (2018) }\end{array}$ & $6 / \mathrm{M}$ & Bicycle & $\begin{array}{l}\text { Left lumbar } \\
\text { above iliac crest }\end{array}$ & Conservative \\
\hline 66 & Shukla., et al. (2018) & $14 / \mathrm{M}$ & Bicycle & LLQ & $\begin{array}{l}\text { Primary closure of perforation with } \\
\text { layered closure }\end{array}$ \\
\hline 67 & $\begin{array}{l}\text { Theodorou CM., et al. } \\
(2019)^{36}\end{array}$ & $7 / \mathrm{M}$ & High-speed MVC & $\begin{array}{l}\text { Left posterolat- } \\
\text { eral flank }\end{array}$ & $\begin{array}{l}\text { Laparotomy with colonic resection-anas- } \\
\text { tomosis and repair of } 3 \text { small bowel inju- } \\
\text { ries with abdominal wall layered closure }\end{array}$ \\
\hline
\end{tabular}

Table 1: Published data about handlebar-induced traumatic hernia. Abbreviations: M: Male; F: Female; LLQ: left Lower Quadrant; RLQ: Right Lower Quadrant; LUQ: Left Upper Quadrant; RUQ: Right Upper Quadrant; RIF: Right Iliac Fossa.

case managed laparoscopically, and 6 cases were managed conservatively because of absence of internal organ injuries and no risk for incarceration or strangulation.

Diagnosis of traumatic hernia is mainly clinical [14,21]. History of blunt focused trauma to the abdomen followed by appearance of a bulge should raise suspicion of the physician to the possibility of traumatic hernia. On examination, there is usually a bruise at the affected area with a handlebar mark in light-skinned individuals around which a mild tender swelling, often reducible, giving an impulse on cough. Otherwise, abdominal examination is unremarkable. Classical signs of hernia are seen in only $50 \%$ of cases. There are cases of patients in which symptoms presented $48 \mathrm{~h}$ after the accident [22]. In severe neglected cases with bowel strangulation with resultant perforation and gangrene, signs of peritonitis develop [21].
In some rare examples, it is possible to have a hernia without the above signs. There are cases in which symptoms developed 48 hours after the trauma [23]. In these circumstances, further radiologic imaging such as ultrasonography (US) has been reported as useful to confirm the diagnosis and to assess intra-abdominal solid organs. Computed tomography (CT) scans can also be useful, as it confirms the diagnosis, define the anatomy of the disrupted abdominal wall layers, evaluate intra-abdominal structures, and distinguish a hernia from a hematoma or soft tissue contusion which are common differential diagnoses $[1,14,21]$. In our patient, presentation was delayed 2 days post traumatic and the diagnosis was clinched by physical examination and confirmed by CT scan. This supports the idea of importance of high index of suspicion in making prompt diagnosis of this type of injury that facilitates timely proper management and improves the outcome and preventing further morbidity and mortality risk. 
An associated scalp hematoma was noted in one case [24]; one patient presented with incarcerated small bowel hernia with no associated visceral injuries [25]. Haimovici., et al. reported a case of traumatic abdominal wall hernia leading to rectus muscle separation with small bowel perforations and mesenteric disruption resulting in massive intraperitoneal bleeding [26]. Hernia may manifest immediately or has delayed presentation and is not always detected during the first examination. In 59 of 67 handlebar hernias published in the literature, the emergence of the hernia was immediate. In 7 patients, however, the hernia was not detected by the physical or ultrasound examination during the first 2 days [27]. In 63 of the 67 reported cases, the hernia was reducible; while four patients presented with an incarcerated hernia. Sixty five reported handlebar hernias were treated surgically some days after the trauma, although in two patient, surgical intervention was performed more than 3 weeks later [27].

In adults, presentation varies substantially and diagnosis may be difficult. Agarwal., et al. 2009 reported two adult cases with traumatic abdominal wall hernia with different presentations and treatment modality. The defect was closed by emergency mesh repair in one patient and the other case had ischemic bowel and underwent resection anastomosis and primary repair of the defect [28].

Abdominal wall bruises in a participant of an MVC has been shown to be a powerful indicator of intra-abdominal injuries in both children and adults. High index of suspicion for these injury types markedly improves their recognition and treatment by appropriately ordering timely observation with serial examinations, further imaging, and surgical exploration [29,30].

Della Porta., et al. 2008 in Italy reported a case of handlebarinduced traumatic hernia of the abdominal wall successfully managed by surgical repair [31].

Hassan., et al. 2008 reported a case of handlebar hernia resulting from an injury sustained during a vehicular collision and discussed the management of such injuries [14].

Goh., et al. 2008 reported a case of bicycle handlebar induced traumatic hernia with jejunal perforation. This case had delayed presentation and diagnosis was confirmed by computed tomography (CT) scan. Surgical exploration with primary repair of the defect is the definitive treatment in such cases [32].

Management of traumatic handlebar hernias is prompt surgical repair to avoid incarceration and strangulation and to restore the anatomical integrity [5,33].

In case of small localized defect, it can be repaired primarily with non-absorbable sutures. With larger defects, prosthetic ma- terials as prolene mesh are often used [18]. Treatment controversies about the management of traumatic abdominal wall hernias are focused on 3 key points: possibility of conservative management, the timing of surgical repair, and the best surgical approach $[14,21]$. The timing of the surgery may be emergent or delayed (elective). The most important determining factor is the possibility of intra-abdominal injury, with immediate operation via midline laparotomy is indicated to enable full exploration, to rule out and deal with any intra-abdominal injury and prevent strangulation of any incarcerated bowel $[13,14,18,21]$. But, if there is no immediate risk of strangulation and no signs of intra-abdominal injury such as blood or feces in the peritoneal cavity, local wound exploration and primary wound closure is usually enough intervention that can be done on an elective basis, and at the same time, conservative management plays an important role as Litton reported successful management of handlebar hernia case, discuss their management, and suggested that immediate surgical intervention may not always be required $[5,15,34,35]$.

Volpe., et al. 2011 adopted the conservative approach in six cases. The defect size was up to $3 \mathrm{~cm}$ and the hernia contained omentum in three cases and bowel loops without incarceration in three cases. Spontaneous healing of the musculature and fascia defect occurred in all patients in 1 - 12 months (mean, 4.4 months) without any complications $[35,36]$.

\section{Conclusion}

Although diagnosis of traumatic abdominal wall hernias is easy to reach on the basis of trauma mechanism and careful abdominal examination, radiologic studies are safe effective auxiliary tool to confirm the diagnosis and assess intra-abdominal structures for associated injuries. Direct closure is feasible in most cases, although prolene or biologic mesh may be required in some cases to achieve tension-free defect closure.

\section{Patient Consent}

Written informed consent was obtained from the parents to publish the images and details. No personal details or photos in this article could lead to identification of the case.

\section{Authorship}

The author attests that he meets the current ICMJE criteria for authorship.

\section{Funding}

None.

\section{Conflicts of Interest}

None.

\section{Bibliography}

1. Killeen KL., et al. "Using CT to diagnose traumatic lumbar hernia”. American Journal of Roentgenology 174.5 (2000): 14131415. 
2. Dimyan W., et al. "Handlebar hernia". Journal of Trauma 20.9 (1980): 812-813.

3. Yarbrough. "Intra-abdominal injury with handlebar hernia: case report and literature review". Journal of Trauma 40.1 (1996): 116-118.

4. Kubalak G. "Handlebar hernia: case report and review of literature". Journal of Trauma 36 (1994): 438-439.

5. Jones BV., et al. "Traumatic abdominal wall hernia". American Journal of Emergency Medicine 7.6 (1989): 667-668.

6. Angelo Mikrogianakis. "Penetrating Abdominal Trauma in Children". Clinical Pediatric Emergency Medicine 3.11 (2010): 217-224.

7. Damschen DD., et al. "Acute traumatic abdominal hernia: case reports". Journal of Trauma 36.2 (1994): 273-276.

8. Jahromi AH., et al. "What we know about management of traumatic abdominal wall hernia: review of the literature and case report". International Surgery 100 (2015): 233-239.

9. Singal R., et al. "Traumatic anterior abdominal wall hernia: a report of three rare cases". Journal of Emergencies, Trauma, and Shock 4.1 (2011): 142-145.

10. Lane CT., et al. "Management of traumatic abdominal wall hernia". The American Surgeon 69.1 (2003): 73-76.

11. Wood RJ., et al. "Traumatic abdominal hernia: a case report and review of the literature". The American Surgeon 54.11 (1988): 648-651.

12. Shiomi H., et al. "Handlebar hernia with intra-abdominal extra-luminal air presenting as novel form of traumatic abdominal wall hernia: report of a case". Journal of Surgery 29.12 (1999): 1280-1284.

13. Goliath J., et al. "Traumatic handlebar hernia: a rare abdominal wall hernia". Journal of Pediatric Surgery 39.10 (2004): e20e22.

14. Hassan KA., et al. "Handlebar hernia: a rare type of abdominal wall hernia". Saudi Journal of Gastroenterology 14.1 (2008): 33-35.

15. Upasani A and Bouhadiba N. "Paediatric abdominal wall hernia following handlebar injury: should we diagnose more and operate less?" BMJ Case Reports 19 (2013): bcr2012008501.

16. Mancel B and Aslam A. "Traumatic abdominal wall hernia: An unusual bicycle handlebar injury". Pediatric Surgery International 19 (2003): 746-747.
17. Ankit Shukla., et al. "Handlebar hernia with triple herniation and perforation: a case report and literature review". Bulletin of Emergency and Trauma 6.3 (2018): 257-261.

18. Dreyfuss DC., et al. "Acute trans-rectus traumatic hernia". Journal of Trauma 26.12 (1986): 1134-1136.

19. Cheng S-P., et al. "Handlebar hernia: a misleading term". Injury Extra 36.8 (2005): 309-311.

20. Mitchiner JC. "Handlebar hernia: diagnosis by abdominal computed tomography". Annals of Emergency Medicine 19.7 (1990): 812-813.

21. Van Bemmel AJ., et al. "Handlebar hernia: a case report and literature review on traumatic abdominal wall hernia in children". Hernia 15.4 (2011): 439-442.

22. Gupta S., et al. "Traumatic abdominal wall hernia". Ulusal Travma Ve Acil Cerrahi Dergisi 17 (2011): 493-496.

23. Losanoff JE., et al. "Handlebar hernia: ultrasonography aided diagnosis". Hernia 6.1 (2002): 36-38.

24. Herbert RJ., et al. "Traumatic abdominal wall hernia in a 7-yearold child". Journal of Pediatric Surgery 8 (1973): 975-978.

25. Kubota A., et al. "Handlebar hernia: case report and review of pediatric cases". Pediatric Surgery International 15.5-6 (1999): 411-412.

26. Ludmila Haimovici., et al. "Handlebar hernia: traumatic abdominal wall hernia with multiple enterotomies. A case report and review of the literature". Journal of Pediatric Surgery 42 (2007): 567-569.

27. Prada AM., et al. "Handlebar hernia: traumatic abdominal wall hernia with multiple enterotomas". European Journal of Pediatric Surgery 14 (2004): 133-136.

28. Agarwal N., et al. "Traumatic abdominal wall hernia in two adults: a case series". Journal of Medical Case Reports 30.3 (2009): 7324.

29. Lutz N., et al. "Incidence and clinical significance of abdominal wall bruising in restrained children involved in motor vehicle crashes". Journal of Pediatric Surgery 39 (2004): 972-975.

30. Paris C., et al. "Predictive indicators for bowel injury in pediatric patients who present with a positive seat belt sign after motor vehicle collision". Journal of Pediatric Surgery 45 (2010): 921-924.

31. Della Porta M., et al. "Traumatic hernia of the abdominal wall: a case report”. Chirurgia Italiana 60.1 (2008): 131-133. 
32. Goh SC., et al. "Traumatic bicycle handlebar hernia". European Journal of Emergency Medicine 15.3 (2008): 179-180.

33. Holmes JH., et al. "Thoracic handlebar hernia: presentation and management". Journal of Trauma 52.1 (2002): 165-166.

34. Litton K., et al. "Management of a traumatic abdominal wall hernia after a bicycle handlebar injury (case report and literature review) ". Journal of Pediatric Surgery 43.4 (2008): e31e32.

35. Volpe A., et al. "Successful conservative management of handlebar hernia in children". Pediatrics International 59 (2017): 105-106.

36. Theodorou CM., et al. "Traumatic posterolateral abdominal wall hernia in a pediatric patient". Journal of Pediatric Surgery Case Reports 43 (2019): 23-25.

\section{Assets from publication with us}

- Prompt Acknowledgement after receiving the article

- Thorough Double blinded peer review

- Rapid Publication

- Issue of Publication Certificate

- High visibility of your Published work

Website: www.actascientific.com/

Submit Article: www.actascientific.com/submission.php

Email us: editor@actascientific.com

Contact us: +919182824667 